\title{
Comparison of failure modes below footings on carbonate and silica sands
}

\section{Jelke Dijkstra}

Visiting Scientist at Centre for Offshore Foundation Systems, Delft University of Technology, Geo-Engineering Section, Delft, The Netherlands

\section{Christophe Gaudin}

Professorial Fellow, Centre for Offshore Foundation Systems, The University of Western Australia, Crawley, WA, Australia

\section{David J. White}

Professorial Fellow, Centre for Offshore Foundation Systems, The University of Western Australia, Crawley, WA, Australia

To investigate the differences in failure mechanisms beneath vertically loaded shallow foundations on silica and carbonate sands by way of particle image velocimetry analysis, $1 \mathrm{~g}$ and centrifuge model tests have been performed. A comparison of silica and carbonate sand behaviour at low stresses and low initial soil density was made possible by $1 \mathrm{~g}$ scaling conditions, while centrifuge conditions focused on high stresses and high soil density. This strategy provided separate insights into the effects of the compressibility and crushability of both sands. Results indicated a distinct difference in failure mode between the two sands. The footing on silica sand exhibited a shallow failure mode with large localised strains close to the soil surface. In contrast, the footing on carbonate sand mobilised strains lower in magnitude over a greater depth. The increased stress level in the centrifuge reduced the surface heave and resulted in deeper failure mechanisms in both sands. The bearing capacity factor for the experimental results could be backcalculated with simple limit analysis solutions, provided that different friction angles were used to account for the variation of stress levels. However, such an approach masks the influence of compressibility on the failure mechanism in the loose and compressible cases by requiring a lower friction angle than is realistically possible.

$\begin{array}{ll}\text { Notation } & \\ D & \text { diameter } \\ e_{0} & \text { initial void ratio } \\ \boldsymbol{g} & \text { acceleration of gravity } \\ I_{D} & \text { relative density } \\ N_{\mathrm{c}} & \text { bearing capacity factor } \\ N_{\mathrm{q}} & \text { bearing capacity factor } \\ N_{\gamma} & \text { bearing capacity factor } \\ Q_{\mathrm{c}} & \text { normalised cone resistance } \\ q_{\mathrm{c}} & \text { cone resistance } \\ q_{\mathrm{ff}} & \text { penetration resistance of full footing } \\ V_{\text {foot }} & \text { volume of footing } \\ \gamma^{\prime} & \text { unit soil weight } \\ \sigma_{\mathrm{v}} & \text { total vertical stress } \\ \sigma_{\mathrm{v}}^{\prime} & \text { effective vertical stress } \\ \varphi_{\mathrm{calc}} & \text { back-calculated friction angle }\end{array}$

\section{Introduction}

Determination of the bearing capacity of shallow foundations is a recurrent research topic, with abundant literature covering analytical investigations (e.g. Davis and Booker, 1971; Prandtl, 1921; Salençon and Matar, 1982; Verruijt, 2003), numerical investigations (e.g. Fenton et al., 2005; Gouvernec and Randolph, 2003; Griffiths, 1982; Ukritchon et al., 2003) and experimental investigations (e.g. Akbas and Kulhawy, 2009; Bienen et al., 2006; Byrne and Houlsby, 1998; Gavin et al., 2009). These investigations focused mainly on footings on clay, for which the bearing capacity factors $N_{\mathrm{c}}$ and $N_{\mathrm{q}}$ are now well defined. The bearing capacity of footings on sands is not as well-established, partly due to the difficulty to establish an exact solution for the bearing capacity factor $N_{\gamma}$. This uncertainty has been reduced by Martin (2005), who established exact solutions for $N_{\gamma}$, using the method of characteristics. Such solutions are, however, limited by the assumption of associated flow as required by the plasticity formulation. Erickson and Drescher (2002) showed that the assumption of associated flow can lead to an over-prediction of bearing capacity for sands, as these generally exhibit a nonassociative behaviour. For carbonate sands, this discrepancy can be even greater, as the high compressibility contributes to a reduction in the bearing capacity (e.g. Coop, 1990; Huang and Airey, 1998; Islam et al., 2002).

It has been demonstrated that the particularities of carbonate sands, while significantly reducing the bearing capacity of the footing (in comparison to silica sand of identical relative 
International Journal of Physical Modelling in Geotechnics Volume 13 Issue 1
Comparison of failure modes

below footings on carbonate

and silica sands

Dijkstra, Gaudin and White density) do not fundamentally affect the general form of the stress-strain response of the soil (Coop, 1990; Foray et al., 1999). However, because of their compressibility, there is a change in the dominant mode of failure that controls bearing capacity. In carbonate sands, a punching form of shear failure, rather than the traditional rigid plastic solution involving heave at the soil surface, tends to control the bearing capacity, as demonstrated by Randolph and Erbrich (1999), Randolph et al. (2004) and Yamamoto et al. (2008). The additional compressibility of carbonate sand compared to silica sand originates from densification of the solid matrix facilitated by a combination of rearrangement and crushing of the grains. These observations were validated by centrifuge tests performed by Finnie and Randolph (1994), although in that study no displacements within the failing soil mass were measured.

Visual observations of failure mechanisms beneath footings on sand are very scarce. Kimura et al. (1985) used radiography to measure displacements in silica sand underneath a flat footing. To the current authors' knowledge no measurements of the failure mechanism below a surface footing on carbonate sand have been previously reported.

The present paper describes experimental observations of the differences in failure mechanism underneath a flat footing in silica and carbonate sands, in order to provide insights associated with the reduction in bearing capacity observed for carbonate sands. Tests were undertaken at $1 \boldsymbol{g}$ and in a geotechnical centrifuge, hence exploring differences in stress levels over two orders of magnitude.

\section{Test set-up and protocol}

\subsection{Test programme overview}

The investigation was performed in two stages. Tests were first performed under $1 \boldsymbol{g}$ conditions, at low stress levels. In this case, grain crushing is minimal during foundation loading, relative to the centrifuge case. Volumetric compression results from both the increase of mean effective stress and the increase of deviatoric stress (Randolph and Erbrich, 1999). The deviatoric response is dependent on the soil state; that is, the current combination of stress level and density relative to the critical state. Consequently, conditions at depth in the field, which typically involve high stresses, can best be replicated under $1 g$ conditions, where stress levels are low, by using initially loose samples. In this way, the soil state is comparable, and thus also is the tendency for contractile or dilatant behaviour (e.g. Fellenius and Altaee, 1994).

In the second stage, tests using an identical footing and the same procedures were performed in a geotechnical centrifuge at a centrifuge acceleration of $100 \mathrm{~g}$, creating higher stress levels, well into the range where grain crushing is evident in carbonate sands. This testing strategy enabled failure mechanisms comprising different relative quantities of grain crushing and rearrangement processes to be observed, indicating the respective influence of the two phenomena on the compressibility and bearing capacity.

The tests were performed in the University of Western Australia (UWA) drum centrifuge in sample boxes with specific ancillary equipment to suit PIV analysis (White et al., 2005). This testing arrangement has been used successfully for numerous previous projects (see for instance Gaudin et al., 2009).

\subsection{PIV image analysis}

Particle image velocimetry (Sutton et al., 1983; Westerweel, 1993; White et al. 2003) is now a common technique in geotechnical centrifuge modelling. A PIV algorithm is used to analyse the digital images acquired during testing. In this study, the area of interest was extracted from each image before being divided into 5000 interrogation patches, each covering a zone of soil approximately $1 \mathrm{~mm}^{2}$. Each of these patches was tracked using a cross-correlation algorithm, to identify the movement of that patch of soil between a pair of images, to a measurement precision of $\sim 10 \mu \mathrm{m}$ for the field of view used during these experiments. Before processing, each image was corrected for image distortion arising from the noncoplanarity of the image and object planes, and non-linearity within the image resulting from lens aberrations. The use of PIV analysis requires that a half-symmetrical footing model is used, which in these tests was placed in a rectangular strongbox, against a transparent poly(methyl methacrylate) window. For reference purposes a full footing was also installed in the same conditions.

\subsection{Test models and set-up}

Tests were performed in strongboxes with dimensions $164 \times$ $257 \times 160 \mathrm{~mm}(W \times L \times H)$, with a transparent window on one side. The window was equipped with markers to simplify the subsequent lens correction of each image (White et al., 2005). The diameter $D$ of the footing was chosen such that it was at least five diameters away from the nearest boundary, resulting in a $25 \mathrm{~mm}$ diameter footing. To avoid any scale effect arising from the relative sizes of the footing and the grains, it is necessary for the ratio $D / D_{50}$ to be higher than 100 (Balachowski, 1995), which was satisfied for all of the sands used in this study.

Models of a whole and half-circular footing were manufactured from aluminium, with dimensions given in Figure 1. The half-model features a $1 \mathrm{~mm}$ diameter O-ring on the edge of the side facing the window, in order to prevent the ingress of soil particles between the footing and window. However, in the $1 g$ tests the contact pressure was insufficient to ensure a complete 
Comparison of failure modes below footings on carbonate and silica sands

Dijkstra, Gaudin and White
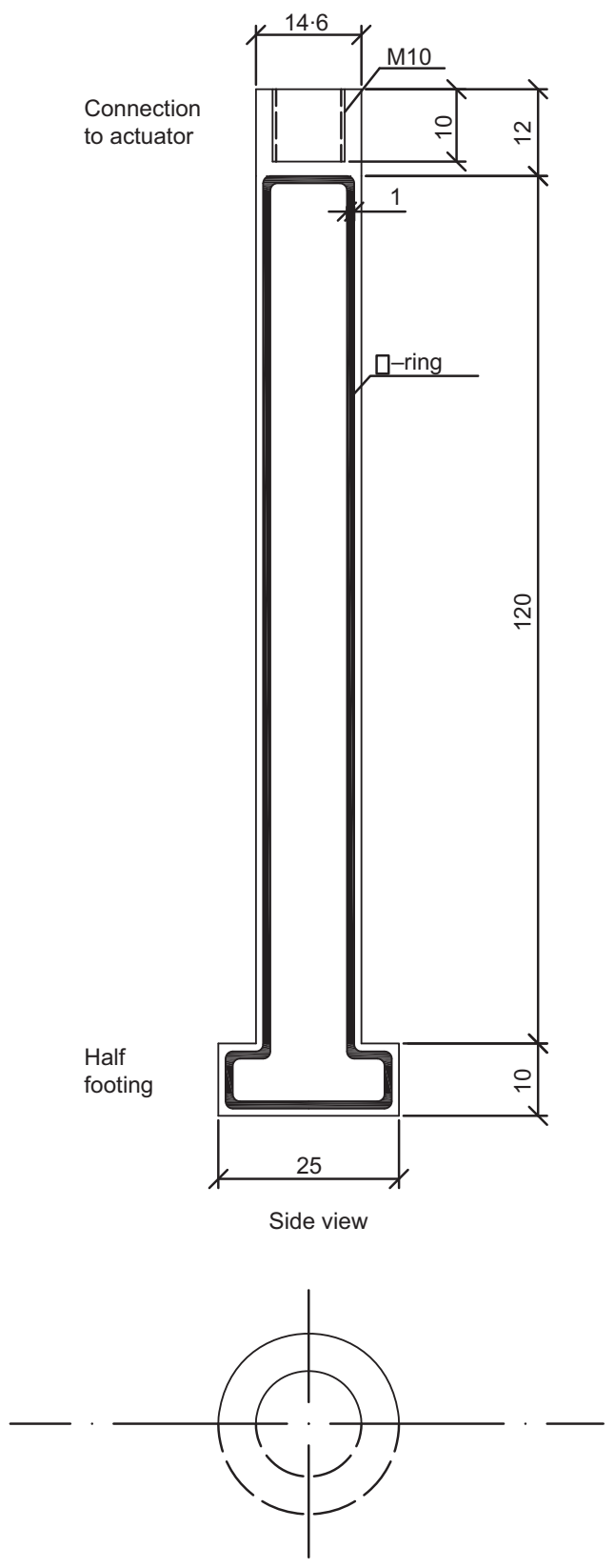

Plan view

Figure 1. Side view of the half and full footing; measures in $\mathrm{mm}$

seal and a small quantity of soil became lodged between the footing and the window, slightly affecting the quality of the observations.

\subsection{Loading system and instrumentation}

Loading of the footing was applied by the standard actuator and motion control system of the UWA centrifuges (De Catania et al., 2010) for both the $1 \mathrm{~g}$ tests and the centrifuge tests. The load was applied under displacement control, at a rate of $0.1 \mathrm{~mm} / \mathrm{s}$, to provide a sufficiently high image acquisition rate (with 1 frame per second this yielded a maximum displacement of $0.1 \mathrm{~mm}$ between photographs, which is approximately 1 pixel of movement). The applied vertical load was measured with a UWA-made S-shaped load cell, while settlements were monitored by an encoder on the actuator. Data acquisition was achieved using the wireless data acquisition system developed at UWA (Gaudin et al., 2010).

Digital images were taken with a Canon Powershot S80 compact camera. Subsequent processing of the digital images was performed with a PIV algorithm that applies a spatial Blackman filter before cross-correlating the interrogation windows in the frequency domain (e.g. Eckstein et al., 2008). The contrast of the sand particles was such that no artificial additives were required to create extra contrast.

\subsection{Sample preparation and test programme}

Three different sands were used for testing: a natural carbonate sand $\left(D_{50}=0 \cdot 120 \mathrm{~mm}\right)$ dredged from the North West Shelf of Western Australia, and two industrially silica sands: a fine one $\left(D_{50}=0.060 \mathrm{~mm}\right)$ and a coarse one $\left(D_{50}=0.250 \mathrm{~mm}\right)$. Figure 2 shows that the particle grading of the carbonate sand falls in between the grading of the two silica sands.

A similar procedure has been followed for all tests and all samples. A consistent loose to medium dense soil sample was prepared by carefully raining the sand through tap water, leading to fully saturated samples. Additional densification was subsequently performed by tapping the strongbox from all sides.

Table 1 presents the testing programme, showing the type of sand used for each test, along with the initial void ratio $e_{0}$ for each sample. In total, six samples were prepared for $1 g$ testing and two samples were prepared for $100 \mathrm{~g}$ testing. All samples had a relative density lower than $35 \%$, qualifying the samples as loose. In each sample, two footing load tests were performed: one on a semi-circular half-footing and one on a circular footing.

The half-footing was installed along the transparent wall, so subsequent PIV analysis could be undertaken. After completion of the half-footing test, the footing was extracted and the full footing was installed elsewhere within the strongbox so the footing bearing capacity could be measured, without interference from the transparent wall. Following the two footing tests, two or three CPT tests were performed, according to the layout presented in Figure 3.

\subsection{Silica and carbonate sand characterisation}

Cone penetrometer tests (CPT) were performed to characterise the samples. The probe diameter $D_{\mathrm{CPT}}$ resulted in a $D_{\mathrm{CPT}} / D_{50}$ ratio higher than 40 for all tests, which is sufficient to eliminate 


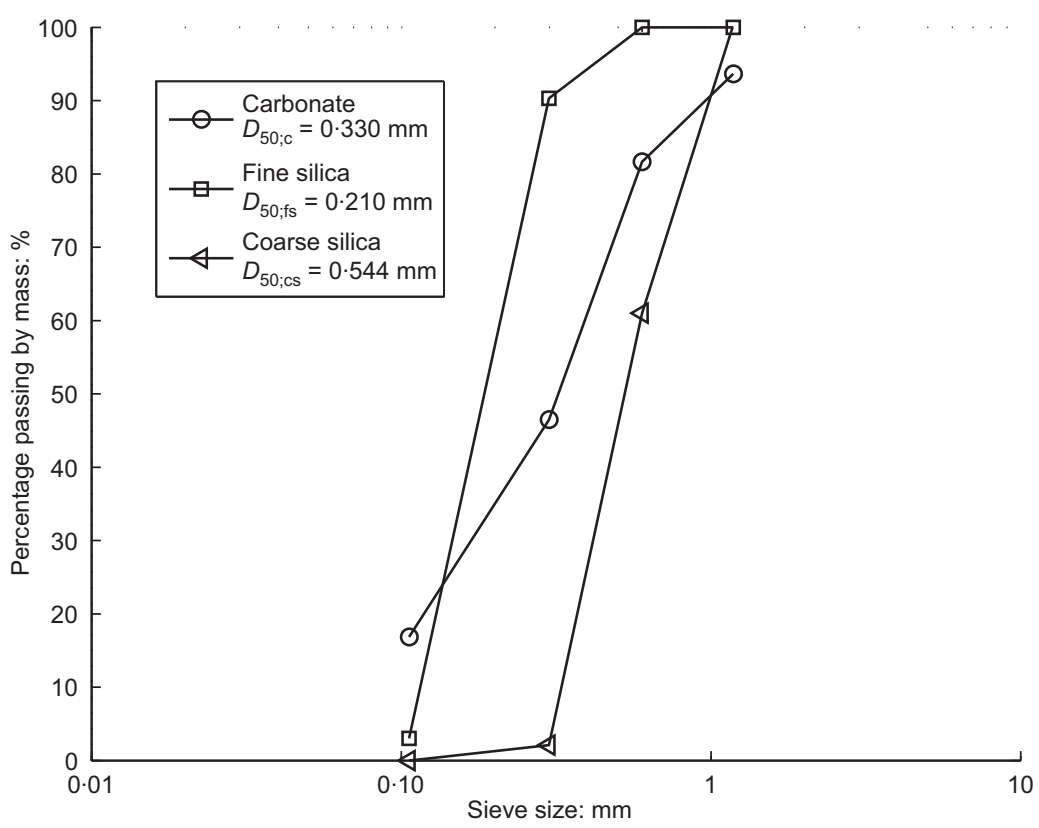

Figure 2. Initial particle grading of the test sands

any effect of particle size on the penetration resistance, at least based on experience from tests in initially loose samples (Balachowski, 1995) ( $D_{\mathrm{CPT}}$ is $10 \mathrm{~mm}$ for the $1 \boldsymbol{g}$ tests and $6 \mathrm{~mm}$ for the centrifuge tests). Both probes feature a load cell located above the apex to measure the tip penetration resistance. CPT tests were performed at different locations within the soil at a penetration rate of $0.5 \mathrm{~mm} / \mathrm{s}$. Figure 3 presents a plan view of the location of the CPTs, with respect to the location of the half and full footing tests. CPTs were performed at a centre-tocentre separation of $0 D$ and $3 \cdot 4 D$ (with $D=25 \mathrm{~mm}$ ) from the footing tests (i.e. one CPT was directly into the centre of the site of the footing test).

Further soil characterisation was undertaken after the tests by extracting material from an undisturbed reference location and from below the footing, in order to investigate the effect of the footing loading on the particle size distribution. To improve the reliability of the sieve analyses the sample sizes were augmented by combining samples from multiple tests in similar material.

\section{Testing results}

Results are first presented and interpreted with respect to the penetration resistance between tests and the CPT data. The interpretation then focuses on the soil displacements and resulting strains in the soil under the footing after $0.4 D$ of penetration. Both interpretations are then associated with analysis of the change in particle size distribution below the footing.

\subsection{CPT results}

Figure 4(a) shows the raw CPT penetration resistance profiles at the undisturbed reference location for all samples. Note that the horizontal axis uses a log scale in order to separate the $1 \mathrm{~g}$

\begin{tabular}{lllllr}
\hline Test no. & Name & Sand type & $D_{50}: \mathrm{mm}$ & $e_{0}$ & $I_{D}: \%$ \\
\hline 1 & C1 & Carbonate & $0 \cdot 330$ & $2 \cdot 33$ & 7 \\
2 & C2 & Carbonate & $0 \cdot 330$ & $2 \cdot 15$ & 30 \\
3 & S1 & Fine silica & $0 \cdot 210$ & $0 \cdot 776$ & 36 \\
4 & S2 & Fine silica & $0 \cdot 210$ & $0 \cdot 793$ & 29 \\
5 & CS1 & Coarse silica & $0 \cdot 544$ & $0 \cdot 773$ & 6 \\
6 & CS2 & Coarse silica & $0 \cdot 544$ & $0 \cdot 745$ & 29 \\
$7100 g$ & C1ng & Carbonate & $0 \cdot 330$ & $2 \cdot 14$ & 31 \\
$8100 g$ & S1ng & Fine silica & $0 \cdot 330$ & $0 \cdot 781$ & 35
\end{tabular}

Table 1. Test overview 


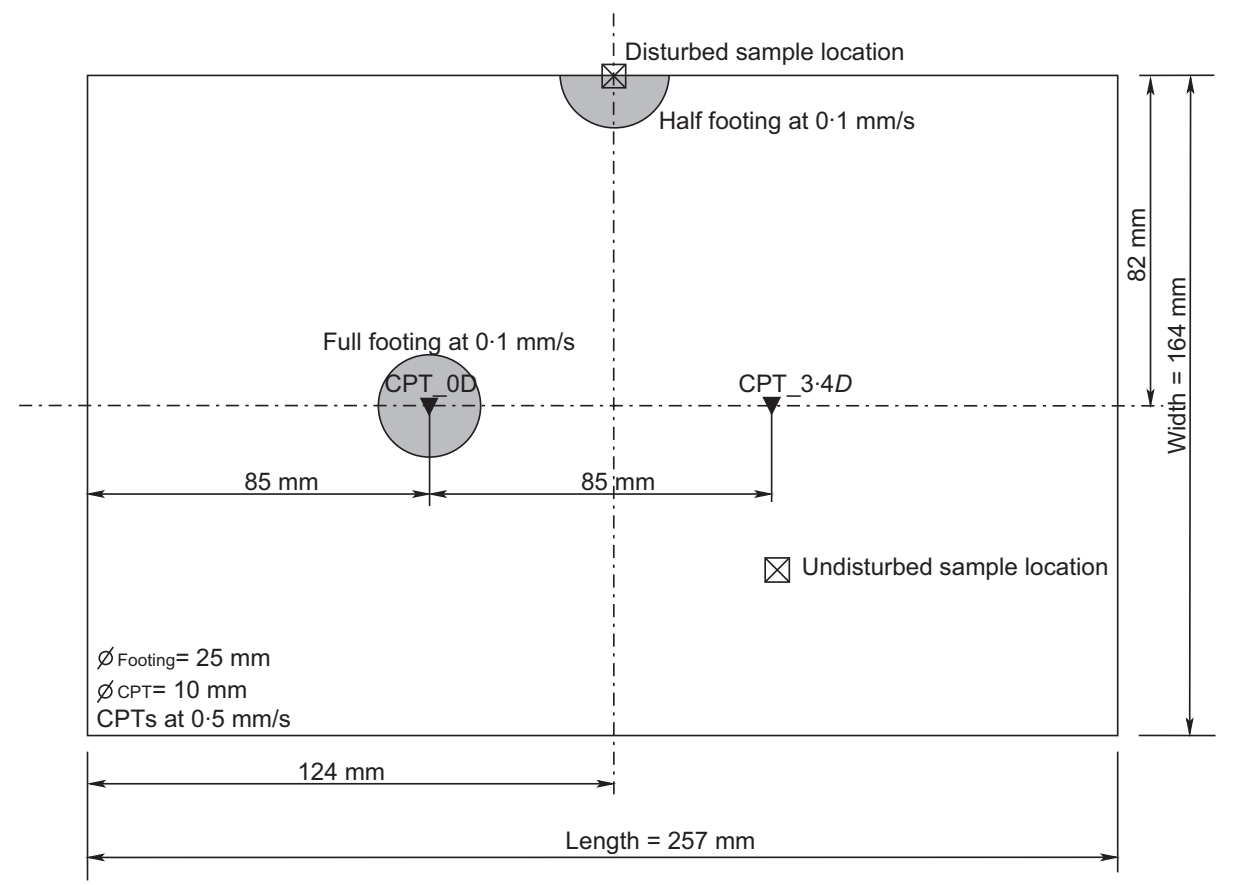

Figure 3. Boundary conditions in the test; plan view;

measurements in $\mathrm{mm}$

and $100 \mathrm{~g}$ data. For a more accurate comparison, results are normalised in Figure 4(b), using a linear scale. The measured $q_{\mathrm{c}}$ has been normalised with the effective and total vertical stress, assuming drained conditions, following Been et al. (1986)

1. $Q_{\mathrm{c} ; 3 \cdot 4 D}=\frac{q_{\mathrm{c} ; 3 \cdot 4 D}-\sigma_{\mathrm{v}}}{\sigma_{\mathrm{v}}^{\prime}}$

All penetration resistance profiles are plotted against the normalised penetration depth, defined as the penetration depth divided by the cone diameter. The results for the $1 g$ tests show the average response of two tests; that is, test 1 and 2, test 3 and 4 and test 5 and 6 in Table 1.

As expected, the penetration resistance at $100 \mathrm{~g}$ is higher than at $1 \mathrm{~g}$, by a factor of 3 for the silica sand and by a factor of 2 for the carbonate sand. The strength of the carbonate material at low stress levels is higher than that of the silica sands. However, at high stress levels the increase in strength for the carbonate material is less than for the silica sands. This difference between the two sands results from the relatively larger volumetric compressibility of the carbonate sand, when compared to the silica sands.

Figure 4(c) presents the results of the CPTs performed in the centre of the footing location after penetration and removal of the footing (i.e. in sheared material). The results are normalised by the readings from the undisturbed location; that is

2. $Q_{\mathrm{c} ; 0 D}=\frac{q_{\mathrm{c} ; 0 D}}{q_{\mathrm{c} ; 3 \cdot 4 D}}$

Two distinct responses are observed at $1 \mathrm{~g}$ and at $100 \mathrm{~g}$. At $1 \mathrm{~g}$, both carbonate and coarse silica sand exhibit a reduction in cone penetration resistance after being sheared by the footing loading. In contrast, the fine silica sand exhibits an increase in penetration resistance of about $20 \%$. The coarser, more angular material seems to loosen while the fine material appears to densify.

At $100 \mathrm{~g}$, all materials exhibit a significant increase in resistance in the top $20 \mathrm{~mm}$ at the disturbed location, and no changes below. It is noteworthy that the magnitude of the increase is largest for the carbonate sand. Again, the differences in cone penetration resistance at $1 \mathrm{~g}$ and $100 \mathrm{~g}$ are primarily accounted for by the low stress conditions.

\subsection{Footing resistance}

The raw data of the full footing tests are presented in Figure 5(a), using a logarithmic scale clearly to differentiate the $1 \boldsymbol{g}$ tests and the centrifuge tests. Displacements and resistance are zeroed with the last reading prior to the footing coming into contact with the soil surface. (Note that the half-footing penetration resistances 


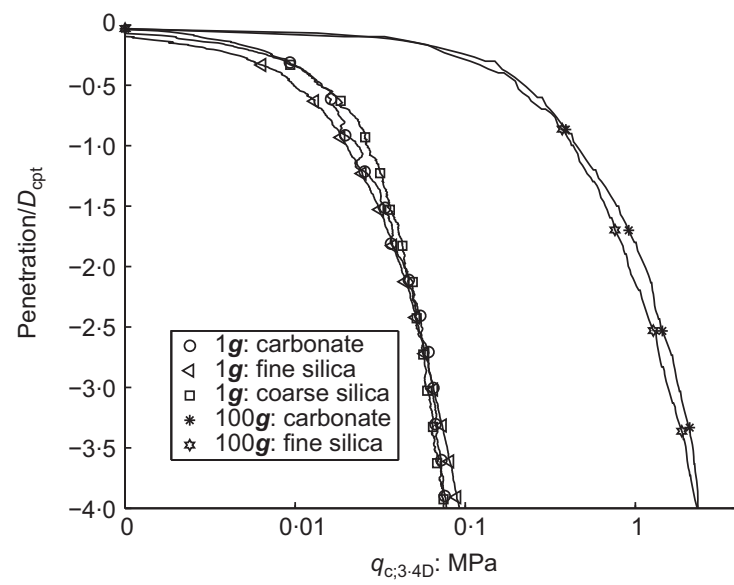

(a)

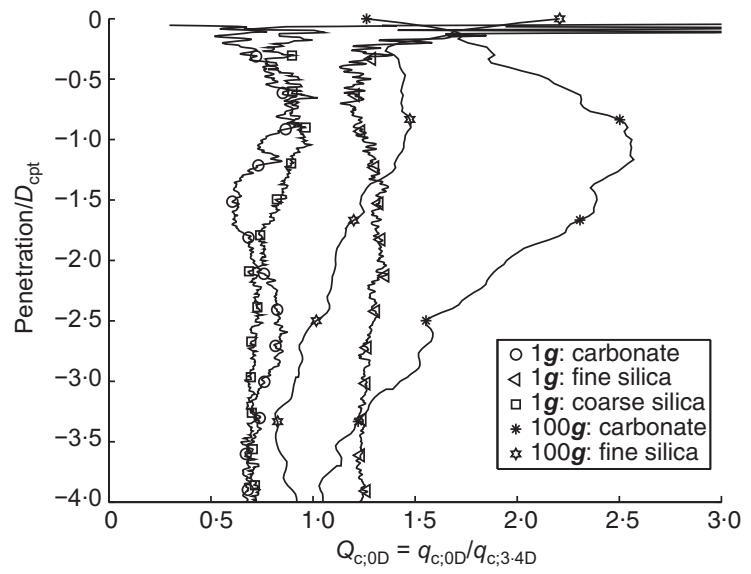

(c)

Figure 4. CPT data for three sand types at $1 \boldsymbol{g}$ and $100 \boldsymbol{g}$; for $1 \boldsymbol{g}$ tests average readings of 2 tests are shown: (a) undisturbed: $3 \cdot 4 D$ : (b) undisturbed: $3 \cdot 4 D$; normalised; (c) disturbed $O D$ normalised with undisturbed readings

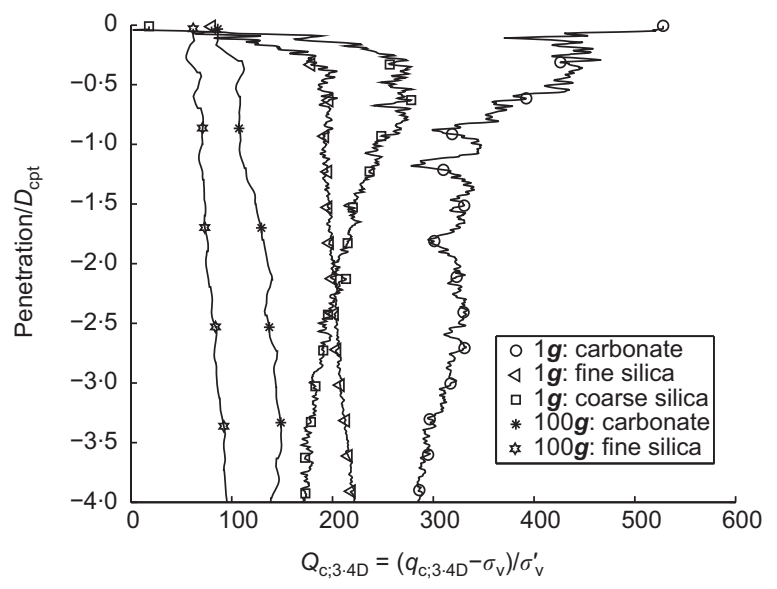

(b) are not used due to the unknown footing-window friction resistance.) As for the CPTs, average readings from two tests are given for the $1 \boldsymbol{g}$ tests, and the displacements are normalised by the footing diameter $D=25 \mathrm{~mm}$. For an easier comparison between the $1 \mathrm{~g}$ and $100 \mathrm{~g}$ test results, the penetration resistance is normalised with the initial vertical effective stress and presented in Figure 5(b). An alternative normalisation is also used, where the footing penetration resistance is divided by the cone penetration resistance. The results are presented in Figure 5(c).

It is evident from Figure 5(c) that the normalised resistance at large displacements converges to a narrow band of $0.75 q_{\mathrm{c}^{-}}$ $1 \cdot 25 q_{\mathrm{c}}$. However, the results for the carbonate sand when tested at $1 \boldsymbol{g}$ still yield a much higher normalised resistance than all other tests. In contrast to the test on fine silica sand, the increased stress level has a significant effect on the response of the carbonate sand. At higher stress levels the normalised resistance is almost equal to that of the silica sands.

The bearing capacity factor $N_{\gamma}$ at $0 \cdot 1 D$ penetration is calculated as follows, neglecting the smaller $N_{\mathrm{q}}$ contribution to the bearing capacity

3. $N_{\gamma}=\frac{2 q_{\mathrm{ff}}}{\gamma^{\prime} D}$

These values are gathered in Table 2 and are discussed later in comparison with theoretical results from limit analysis.

It appears from Figures 5(b) and 5(c), that the normalisation of footing resistance that provides the most consistent results 
Comparison of failure modes below footings on carbonate and silica sands

Dijkstra, Gaudin and White

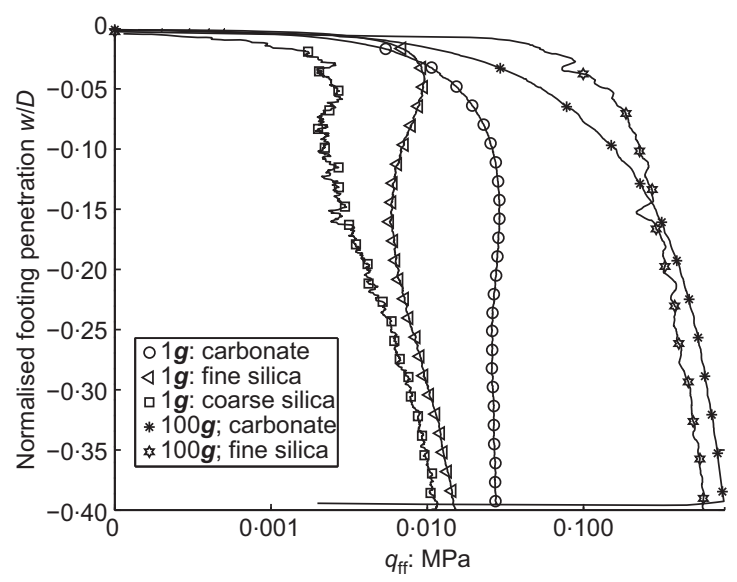

(a)

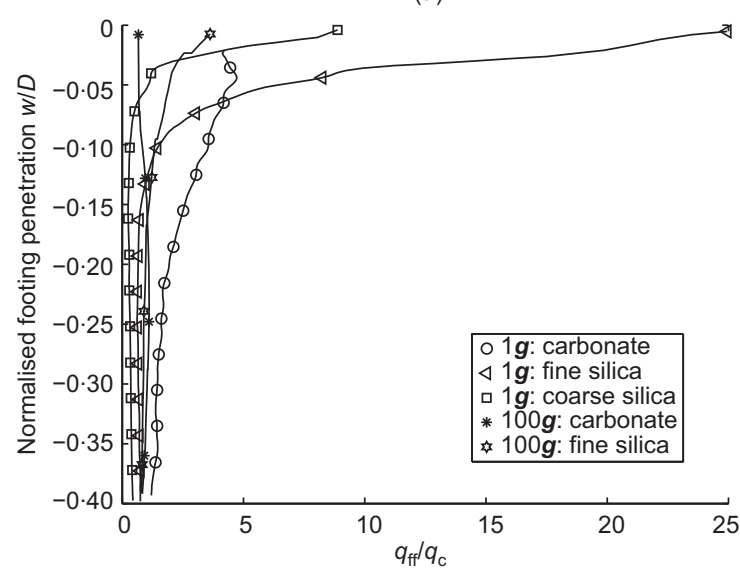

(c)

Figure 5. Load-displacement data for the full footing; for three sand types and two acceleration levels; resistance normalised with stress level or $q_{c}$ : (a) load; (b) load normalised with vertical stress; (c) load normalised with $q_{c}$

across all tests is by the penetration resistance $q_{\mathrm{c}}$ rather than the vertical stress. The cone resistance appears to be affected by stress level, density and friction angle in a similar manner to the footing resistance. In most tests, the footing response stabilises after $0 \cdot 1 D$ of penetration.

\subsection{Soil displacements}

The PIV analysis generates the full trajectory of each patch of soil through the entire penetration process. These trajectories are generally curved, since the direction of motion of each soil element varies as the footing penetrates. It is common practice to plot and interpret only the overall displacement. However, by plotting the displacement trajectories, the intermediate displacements as well as the final positions can be observed in a single figure, hence providing a more complete insight into the footing behaviour. The advantage of using displacement trajectories over solely using vectors between initial and end position is

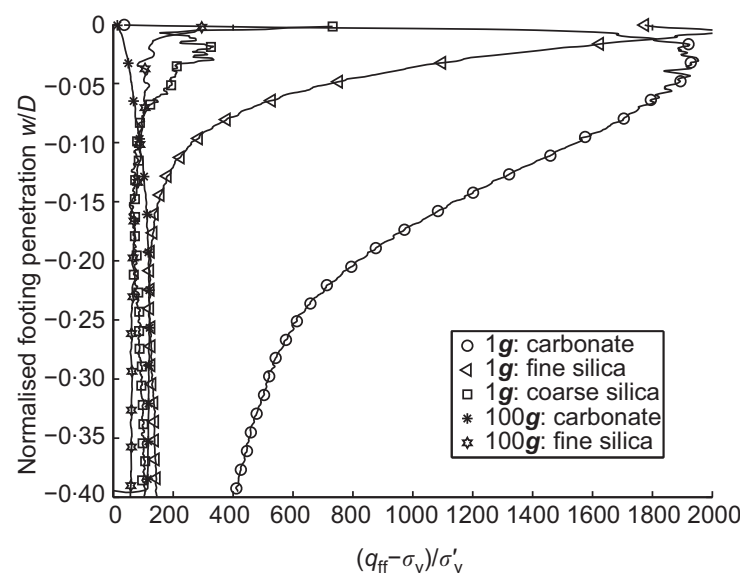

(b) illustrated in Figure 6. All subsequent results show trajectories rather than displacement vectors with the same field of view and length scale. A second order spline interpolation was used to interpolate the raw PIV results onto the same spatial grid with interval of $2 \mathrm{~mm}$ (or $0 \cdot 08 \mathrm{D}$ ) for clearer plotting.

Figures 7(a)-7(d) respectively show the results for the $1 \mathrm{~g}$ and the $100 \mathrm{~g}$ tests. The first two figures group the results by stress level, while the latter two compare the $1 g$ and the $100 g$ results. The results for the $1 g$ tests cover all the soil samples investigated: that is, the carbonate sand, the fine silica sand and the coarse silica sand. Results for only the carbonate and the fine silica sand are available for the $100 \mathrm{~g}$ tests.

A symmetrical failure mode is observed for all tests, indicating successful vertical penetration of the footing and homogeneous sample conditions. It is evident from Figure 7(a) that the $1 \boldsymbol{g}$ 


\begin{tabular}{|c|c|c|c|c|}
\hline Sand type & $D: m$ & $q: \mathrm{kPa}$ & $\gamma^{\prime}: \mathrm{kN} / \mathrm{m}^{3}$ & $\varphi_{\text {calc }}{ }^{\circ}$ \\
\hline Carbonate $1 \boldsymbol{g}$ & 0.025 & $25 \cdot 9$ & $6 \cdot 75$ & $45 \cdot 7$ \\
\hline Silica $1 \boldsymbol{g}$ & 0.025 & $6 \cdot 5$ & $9 \cdot 92$ & $38 \cdot 5$ \\
\hline Carbonate $100 \boldsymbol{g}$ & $2 \cdot 5$ & 160 & $6 \cdot 89$ & $31 \cdot 3$ \\
\hline Silica $100 \boldsymbol{g}$ & $2 \cdot 5$ & 223 & $10 \cdot 3$ & $30 \cdot 8$ \\
\hline
\end{tabular}

Table 2. Back-calculated friction angles based on limit analysis solutions and measured values of penetration resistance, $q$, at $0 \cdot 1 D$ penetration

footing test in carbonate sand results in large vertical displacements with only limited horizontal displacements. This corresponds to a plunging failure mechanism (or oedometric compression), consistent with the high compressibility of the carbonate sand. In contrast, tests at $1 \boldsymbol{g}$ in the finer and coarser silica sands exhibit a shallower failure mode with larger horizontal displacements and soil heave next to the footing, typical of a conventional rigid plastic bearing capacity mechanism.

At $100 \mathrm{~g}$, the tests in silica sand show a typical Prandtl wedgeshaped mechanism, characterised by a penetrating wedge that is more accentuated for a $1 \boldsymbol{g}$ test (Figure 7(d)). The increase in stress level magnified the response for the carbonate sand; that is, an even more localised plunging failure mode was observed (Figure 7(c)).

The differences in displacement response between the carbonate and silica tests at low and high stress levels are further investigated by plotting the vertical displacement profiles in Figure 8(a). The initial and final displacement profiles, for four

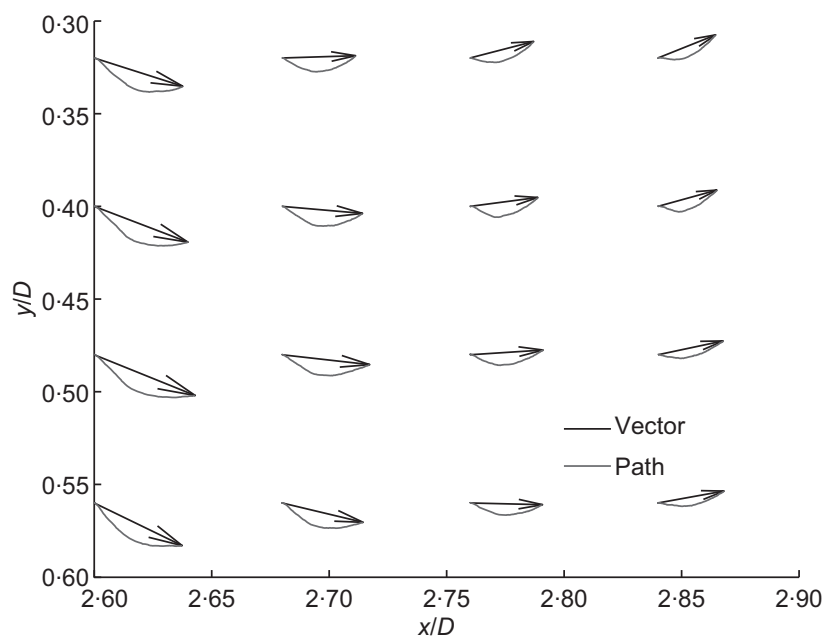

Figure 6. Comparison of vector and path trajectories cross-sections spaced at $0 D, 0 \cdot 5 D, 1 D$ and $1 \cdot 5 D$ underneath the footing, are plotted. Similarly, horizontal displacement profiles are plotted in Figure 8(b) at the same spacing from the centre of the footing. Owing to the symmetry in the failure mechanism, for example as shown in Figures 7(a)-7(d), only one half of the domain is displayed.

The following observations can be made from Figure 8(a) and Figure 8(b).

In the $1 \boldsymbol{g}$ tests the surface trough becomes shallower and wider with increasing depth. The vertical profiles show that below a distance of $1 D$ the penetration effects become negligible (note that the results for the $0 D$ response in Figure 8(a) are somewhat disturbed by particles trapped between the footing and the transparent wall). There are, however, significant differences between the three sand types. Profiles in carbonate sand exhibit deeper displacements, but without lateral movement. This highlights the change in mechanism between the traditional bearing capacity failure, observed for the silica sand, and a plunging mechanism involving oedometric compression that results from the compressibility and crushability of the carbonate sand.

The cross-sections show more clearly that, in the centrifuge tests, a deeper failure mode and wider influence zone at $0 \cdot 5 D$ and $1 D$ below surface level are obtained. Compared to the $1 \mathrm{~g}$ results the surface trough is even shallower and wider with increasing depth, indicating that less dilation is taking place. This is supported by the load-displacement response of the footings, with the shallow failure mechanism resulting in the lowest load. More interestingly, the failure mechanisms are located much deeper for all sands as depicted in Figures 7(c), 7(d) and 8(a). This is particularly the case for the carbonate sand, where the plunging failure mechanism extends below the field of view. This indicates the source of a relatively lower bearing capacity factor in the centrifuge tests; that is, $N_{\gamma ; \text { carb;100 g }}<N_{\gamma ; \text { carb;lg }}$ (see Table 2).

The total volume enclosed by the surface heave next to the footing at maximum penetration, normalised by the 
International Journal of Physical Modelling in Geotechnics Volume 13 Issue 1
Comparison of failure modes below footings on carbonate and silica sands

Dijkstra, Gaudin and White

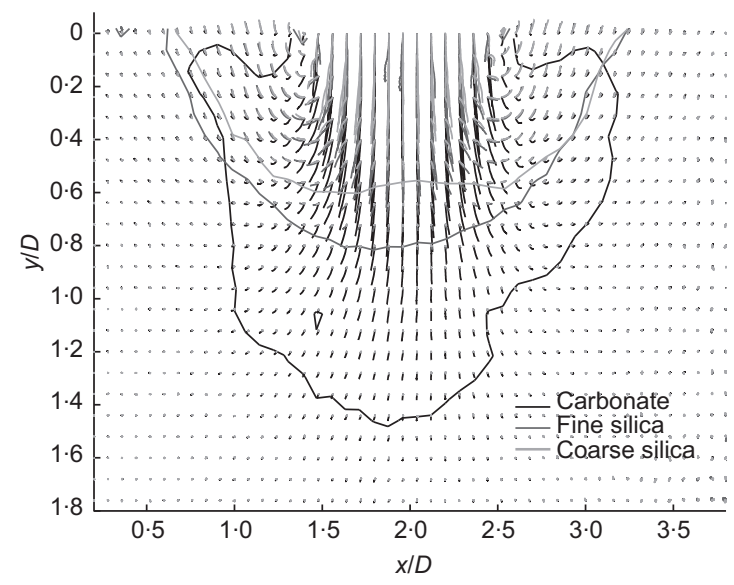

(a)

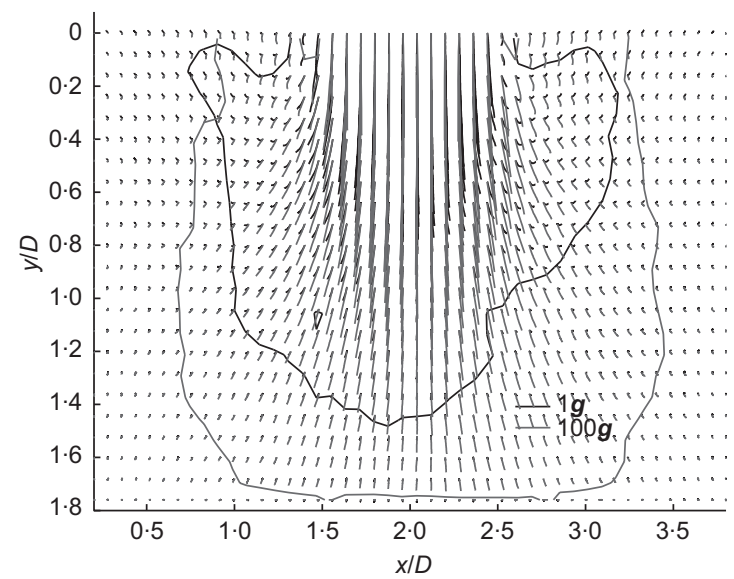

(c)

Figure 7. Displacement trajectories of soil displacements after $0.4 D$ of footing penetration: (a) $1 \boldsymbol{g}$ results; carbonate, silica and coarse silica sands; (b) centrifuge results; carbonate and silica sands; (c) $1 \boldsymbol{g}$ plotted against centrifuge results; carbonate sand; (d) $1 \boldsymbol{g}$ plotted against centrifuge results; silica sand

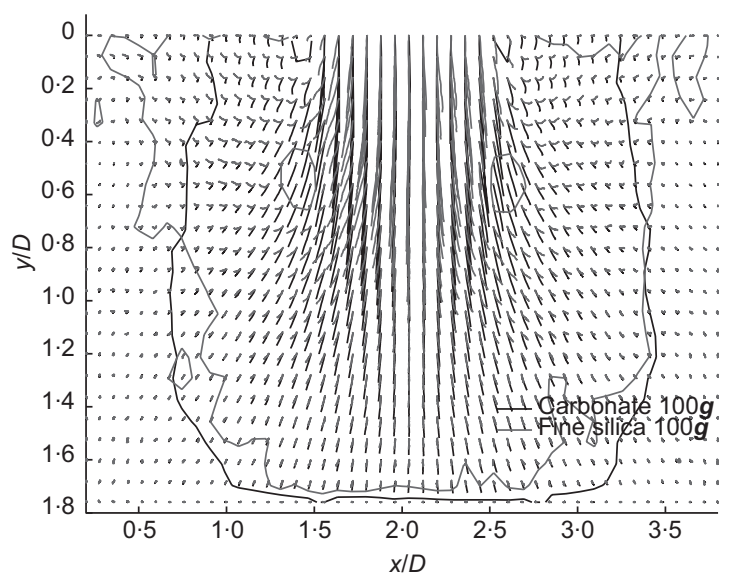

(b)

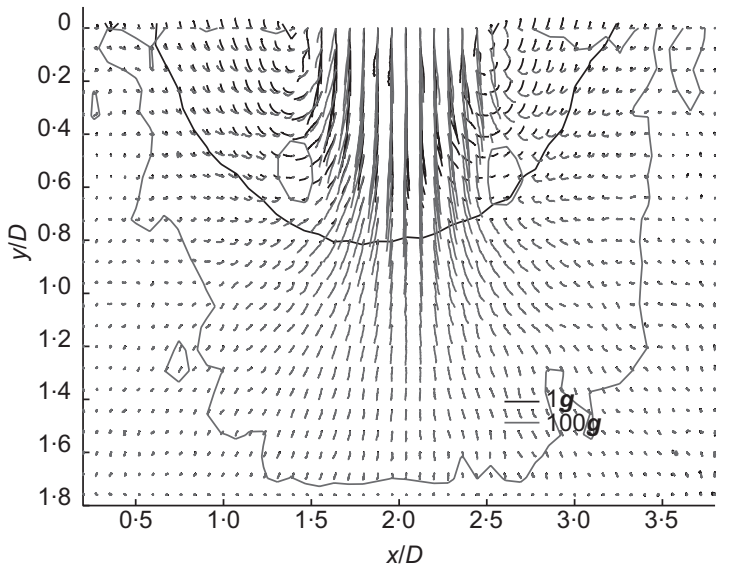

(d) penetrated footing volume, derived from these profiles, amounts to $0 \cdot 27 V_{\text {foot }}, 0 \cdot 55 V_{\text {foot }}$ and $0 \cdot 65 V_{\text {foot }}$ for the $1 g$ carbonate, silica tests and coarse silica tests (not shown), respectively. For all sand types the centrifuge tests did not show any surface heave, indicating that the net soil compression throughout the failure mechanism exceeded the volume of the embedded foundation.

- These observed differences in failure mechanism below a footing for silica and carbonate sands support the outcome of the numerical analysis presented in Yamamoto et al. (2008).

The effects of sand type and increase of stress level on the resulting failure mechanism are summarised in Figure 9. This shows a schematic overview of the general failure mechanisms, which are presented in detail in Figures 7(a)-7(d). The left-hand side indicates the results for the carbonate sand, while the righthand side shows the results for the fine silica sand. There is a narrow and deep plunging failure with predominantly vertical soil displacements for the carbonate sand and a wider shallower mode with larger horizontal displacements for the silica sands.

\section{Comparison with limit analysis calculations of bearing capacity}

The computer program 'ABC' (Martin, 2003) has been used to back-calculate the mobilised friction angle during penetration of the footing, if a rigid plastic failure mechanism is assumed to take place. The results provided by $\mathrm{ABC}$ constitute partial or incomplete lower bound solutions, although for many cases these solutions have been proven to be exact, with the corresponding upper bound failure mechanism yielding the 
Comparison of failure modes below footings on carbonate and silica sands

Dijkstra, Gaudin and White

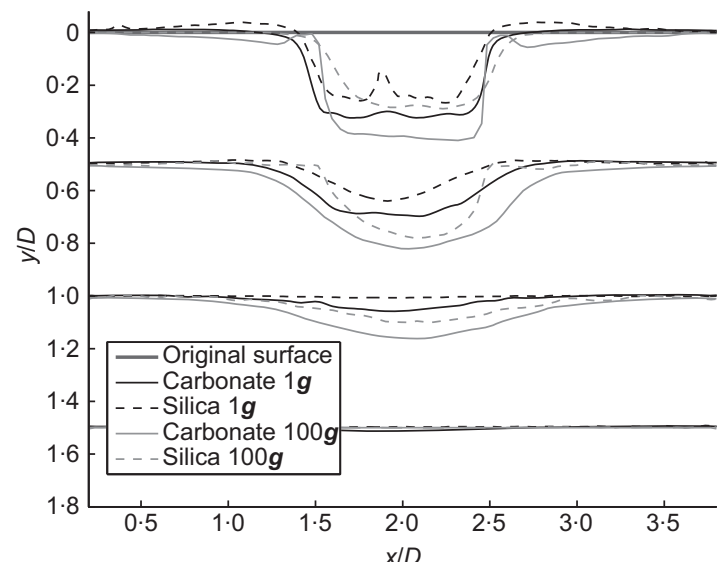

(a)

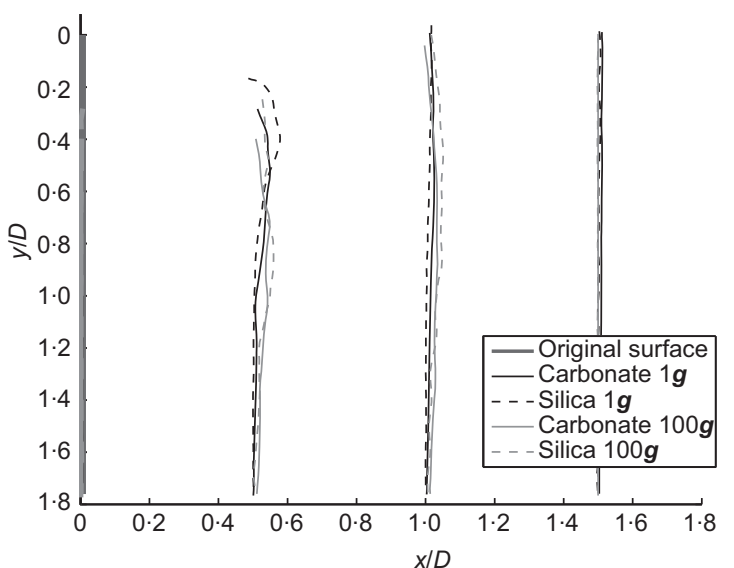

(b)

Figure 8. Horizontal and vertical cross-sections for deformed initial geometry after $0 \cdot 4 D$ of footing penetration: (a) horizontal crosssections at $O D, 0.5 D, 1 D, 1.5 D$; (b) vertical cross-sections at $O D$, $0 \cdot 5 D, 1 D, 1 \cdot 5 D$

same resistance, and the lower bound field being extensible (Martin, 2005).

While it is acknowledged that the crushability of the carbonate sand is not consistent with a rigid-perfectly plastic analysis and that the punching shear mechanism observed in Figure 7 is different to the mechanism assumed by the $\mathrm{ABC}$ programme, limit analysis calculations can be used to estimate the footing bearing capacity, provided that the friction angle is reduced accordingly. This approach, initially suggested by Vesić (1973), is supported by Finnie and Randolph (1994), who demonstrated that treating the foundation response as one of continuous failure, linking the bearing modulus to a classical

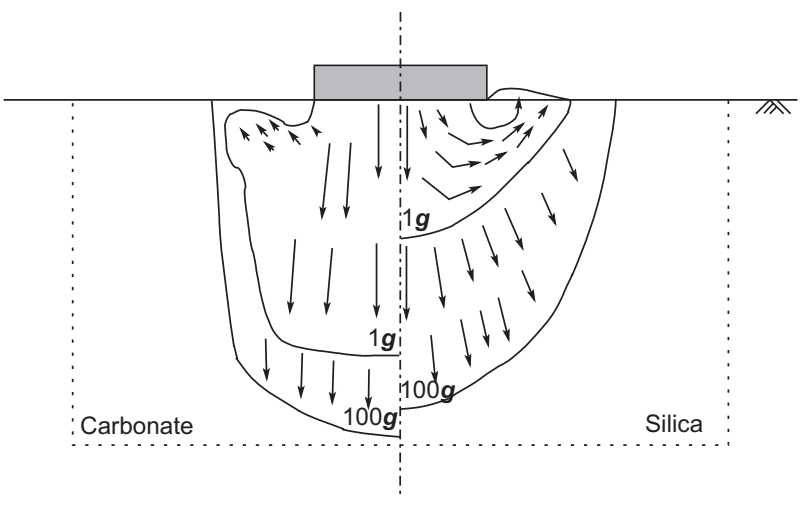

Figure 9. Sketch of general schematic failure mechanism below footing bearing capacity factor, gave good correlation with their experimental data.

Consequently, calculations have been performed using $\mathrm{ABC}$ for the silica and the carbonate sand, using the appropriate effective unit weight in each case. The embedment has been treated as a surcharge equal to $0 \cdot 1 \gamma^{\prime} D$, and the footing base has been modelled as smooth (i.e. mobilising zero shear stress). The friction angle has been varied, until the calculated bearing capacity matches the measured load at $0 \cdot 1 D$ penetration. The results are presented in Table 2.

For the low stress tests, the back-calculated friction angle for the carbonate sand significantly exceeds the corresponding angle for the silica sand. This is consistent with the relative strength of these sands, and results from the angularity and roughness of carbonate grains.

For the higher stress tests, lower values of friction angle are calculated. This is attributable to two effects. First, the influence of stress level on peak strength; at higher stresses, lower peak values of friction angle are mobilised (Bolton, 1986). Second, these back-calculated friction angles are based on the assumption of a rigid plastic failure mechanism. In practice, as noted from the PIV results, the foundation penetration is partly accommodated by volumetric compression, particularly in the centrifuge tests. Consequently, the back-calculated friction angle is likely to be an underestimate of the true angle. This is evident in the value of $31.3^{\circ}$ assessed for the carbonate sand, which is lower than the critical state friction angle. 
International Journal of Physical Modelling in Geotechnics Volume 13 Issue 1
Comparison of failure modes

below footings on carbonate

and silica sands

Dijkstra, Gaudin and White

\section{Conclusions}

$1 \boldsymbol{g}$ and $100 \mathrm{~g}$ tests have been performed on a shallow footing loaded over fine and coarse silica sands and carbonate sand. The results were interpreted both in terms of bearing capacity factors and in terms of soil deformations.

Different failure modes were identified, depending on sand type and stress level. Footings on silica sand exhibited shallow failure modes with large localised strains at shallow depths, while footings on the carbonate sand mobilised strains lower in magnitude over a larger range of depths. An increased stress level reduced the surface heave and resulted in a deeper localised failure mechanism for all sands.

The bearing capacity factor for the experimental results could be back-analysed with simple limit analysis solutions, which were used to estimate an operative friction angle at failure. For the low stress tests a higher angle of internal friction was required to predict the experimental results. These differing back-calculated friction angle highlight the differences in friction angle owing to particle type, soil density and stress level. However, they are also likely to be in error, particularly for the compressible carbonate sands, owing to the penetration being partly accommodated by volumetric compression beneath the footing rather than heave (as is assumed in the limit analysis solutions).

\section{Acknowledgements}

The experimental work described in this paper was performed at the Centre for Offshore Foundations, which is currently supported as a node of the Australian Research Council Centre of Excellence for Geotechnical Science and Engineering. The third author acknowledges support from the Australian Research Council through their Future Fellowships programme.

\section{REFERENCES}

Akbas SO and Kulhawy FH (2009) Axial compression of footings in cohesionless soils. II: bearing capacity. Journal of Geotechnical and Geoenvironmental Engineering 135(11): 1575-1582.

Balachowski L (1995) Différents aspects de la modélisation physique du comportement des pieux: Chambre d'Etalonnage et Centrifugeuse. Dissertation, l'Institut National Polytechnique de Grenoble, France (in French).

Been K, Crooks JHA, Becker DE and Jefferies MG (1986) The cone penetration test in sands: part I, state parameter interpretation. Géotechnique 36(2): 239-249.

Bienen B, Byrne BW, Houlsby GT and Cassidy MJ (2006) Investigating six-degree-of-freedom loading of shallow foundations on sand. Géotechnique 56(6): 367-379.

Bolton MD (1986) The strength and dilatancy of sands. Géotechnique 36(1): 65-78.
Byrne BW and Houlsby GT (1998) Model Testing of Circular Flat Footings on Uncemented Loose Carbonate Sand: Experimental Data. University of Oxford, UK, Report no. OUEL 2192/98.

Coop MR (1990) The mechanics of uncemented carbonate sands. Géotechnique 40(4): 607-626.

Davis EH and Booker JR (1971) The bearing capacity of strip footings from the standpoint of plasticity theory. Proceedings of 1st Australia-New Zealand Conference on Geomechanics, Melbourne, Australia, pp. 276-282.

DeCatania S, Breen J, Gaudin C and White DJ (2010) Development of a multiple-axis actuator control system. In Proceedings of 7th International Conference on Physical Modelling in Geotechnics, Zurich, Switzerland, pp. 325-330.

Eckstein AC, Charonko J and Vlachos P (2008) Phase correlation processing for DPIV measurements. Experiments in Fluids 45(3): 485-500.

Erickson HL and Drescher A (2002) Bearing capacity of circular footings. Journal of Geotechnical and Geoenvironmental Engineering ASCE 128(1): 38-43.

Fellenius BH and Altaee AA (1994) Stress and settlement of footings in sand. In Vertical and Horizontal Deformations of Foundations and Embankments (Yeung AKW and Feaalio G (eds)). ASCE, New York, NY, USA, Geotechnical Special Publication no. 40, vol. 2, pp. 1760-1773.

Fenton GA, Griffiths DV and Cavers W (2005) Resistance factors for settlement design. Canadian Geotechnical Journal 42(5): $1422-1436$.

Finnie IMS and Randolph MF (1994) Bearing response of shallow foundations in uncemented calcareous soil. Proceedings of International Conference on Centrifuge 94, Singapore, pp. $535-540$.

Foray P, Colliat JL and Nauroy JF (1999) Fundamental mechanisms governing the behaviour of carbonate sands and influence on design of deep foundations. In Proceedings of the 2nd International Conference on Engineering for Calcareous Sediments, Bahrain. Balkema, Rotterdam, the Netherlands, pp. 55-68.

Gaudin C, Tham KH and Ouahsine S (2009) Keying of plate anchors in NC clay under inclined loading. International Journal of Offshore and Polar Engineering 19(2): 135-142

Gaudin C, White DJ, Boylan N, Breen J, Brown T and De Catania S (2010) A miniature high speed wireless data acqisition system for geotechnical centrifuges. In Proceedings of 7 th International Conference on Physical Modelling in Geotechnics, Zurich, Switzerland, pp. 229-234.

Gavin K, Adekunte A and O'Kelly B (2009) A field investigation of vertical footing response on sand. Proceedings of the Institution of Civil Engineers - Geotechnical Engineering 162(5): 257-267.

Gouvernec S and Randolph M (2003) Effect of strength nonhomogeneity on the shape of failure envelopes for 
Comparison of failure modes below footings on carbonate and silica sands

Dijkstra, Gaudin and White combined loading of strip and circular foundations on clay. Géotechnique 53(6): 575-586.

Griffiths DV (1982) Computation of bearing capacity factors using finite elements. Géotechnique 32(3): 195-202.

Huang JT and Airey DW (1998) Properties of artificially cemented carbonate sand. Journal of Geotechnical and Geoenvironmental Engineering ASCE, 124(6): 492-499.

Islam MK, Carter JP and Airey DW (2002) Three dimensional elasto-plastic finite element analysis of offshore circular foundations resting on carbonate sands and subjected to inclined loads. Journal of Civil Engineering, The Institution of Engineers Bangladesh CE30(1): 25-41.

Kimura T, Kusakabe O and Saitoh K (1985) Geotechnical model tests of bearing capacity problems in a centrifuge. Géotechnique 35(1): 33-45.

Martin CM (2003) New software for rigorous bearing capacity calculations. Proceedings of International Conference on Foundations, Dundee, pp. 581-592.

Martin CM (2005) Exact bearing capacity calculations using the method of characteristics. Proceedings of 11th International Conference of IACMAG, Turin, vol. 4, pp. 441-450.

Prandtl L (1921) Über die Eindringungsfestigkeit (Härte) plastischer Baustoffe und die Festigkeit von Schneiden. Zeitschrit für Angewandte Mathematik und Mechanik 1, 15-20 (in German).

Randolph MF and Erbrich C (1999) Design of shallow foundations for calcareous sediments. In Proceedings of the 2nd International Conference on Engineering for Calcareous Sediments, Bahrain. Balkema, Rotterdam, the Netherlands, pp. 361-378.

Randolph MF, Jamiolkowski MB and Zdravkovic L (2004) Load carrying capacity of foundations. In Advances in
Geotechnical Engineering: The Skempton Conference (Jardine RJ, Potts DM and Higgins KG (eds)). Thomas Telford, London, UK, vol. 1, pp. 207-240.

Salençon J and Matar M (1982) Capacité portante des fondations superficielles circulaires. Journal de Mécanique Théorique et Appliquée 1(2): 237-267 (in French).

Sutton MA, Wolters WJ, Peters WH, Ranson WF and McNeill SR (1983) Determination of displacements using an improved digital correlation method. Image and Vision Computing 1(3): 133-139.

Ukritchon B, Whittle AJ and Klangvijit C (2003) Calculations of bearing capacity factor $\mathrm{N} \gamma$ using numerical limit analyses. Journal of Geotechnical and Geoenvironmental Engineering ASCE, 129(6): 468-474.

Verruijt A (2003) Lecture Notes: Offshore Soil Mechanics. Technical University of Delft, the Netherlands.

Vesić AS (1973) Analysis of ultimate loads of shallow foundations. Journal of the Soil Mechanics and Foundations Division, ASCE 99(SMI): 45-73.

Westerweel J (1993) Digital Particle Image Velocimetry. Dissertation, Delft University of Technology, the Netherlands.

White DJ, Take WA and Bolton MD (2003) Soil deformation measurement using particle image velocimetry (PIV) and photogrammetry. Géotechnique 53(7): 619-631.

White DJ, Randolph MF and Thompson B (2005) An image-based deformation measurement system for the geotechnical centrifuge. International Journal of Physical Modelling in Geotechnics 5(3): 1-12.

Yamamoto N, Randolph MF and Einav I (2008) Simple formulas for the response of shallow foundations on compressible sands. International Journal of Geomechanics 8(4): 230-239.

\section{WHAT DO YOU THINK?}

To discuss this paper, please email up to 500 words to the editor at journals@ice.org.uk. Your contribution will be forwarded to the author(s) for a reply and, if considered appropriate by the editorial panel, will be published as discussion in a future issue of the journal.

International Journal of Physical Modelling in Geotechnics relies entirely on contributions sent in by civil engineering professionals, academics and students. Papers should be 2000-5000 words long (briefing papers should be 1000 2000 words long), with adequate illustrations and references. You can submit your paper online via www.icevirtuallibrary.com/content/journals, where you will also find detailed author guidelines. 